\title{
PERBANDINGAN AKTIVITAS ANTIOKSIDAN DARI SEDUHAN 3 MERK TEH HITAM (Camellia sinensis (L.) Kuntze) DENGAN METODE SEDUHAN BERDASARKAN SNI 01-1902-1995
}

\author{
${ }^{1}$ Leni Purwanti, ${ }^{2}$ Undang Ahmad Dasuki, ${ }^{3}$ Allysa Rachma Imawan \\ 1,2,3 Program Studi Farmasi , Fakultas Matematika dan Ilmu Pengetahuan Alam, Kelompok Keahlian Farmasi \\ Bahan Alam, Universitas Islam Bandung \\ J1. Rangga Malela No. 1 Bandung, Indonesia

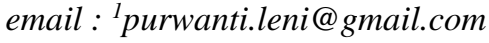

\begin{abstract}
ABSTRAK
Teh (Camellia sinensis (L.) Kuntze) adalah tanaman yang banyak ditemukan di daerah pegunungan Asia yang diketahui memiliki manfaat baik bagi tubuh dan mengandung antioksidan. Antioksidan polifenol memberikan keuntungan bagi kesehatan, yaitu berperan dalam melawan radikal bebas yang berbahaya bagi tubuh. Tujuan dari penelitian ini adalah untuk mengetahui aktivitas antioksidan pada teh hitam dari beberapa merk dagang teh (Merk A, Merk B dan Merk C) menggunakan metode DPPH dengan standar penyeduhan teh sesuai dengan yang diatur dalam SNI 01-1902-1995 mengenai teh hitam. Hasil penelitian menunjukkan bahwa dari ketiga merk teh yang diuji, teh hitam Merk B memiliki aktivitas tertinggi dengan nilai $\mathrm{IC}_{50} 1800 \mu \mathrm{g} / \mathrm{mL}$ dibandingkan dengan vitamin $\mathrm{C}$ dengan nilai $\mathrm{IC}_{50}$ $6,32 \mu \mathrm{g} / \mathrm{mL}$.
\end{abstract}

Kata Kunci: Antioksidan, DPPH, teh hitam, tiga merk, vitamin C

\begin{abstract}
Tea (Camellia sinensis (L.) Kuntze) is a plant widely found in Asian mountain regions that are known to have good benefits to the body and contain antioxidants. Polyphenol provides health benefit which give an important role in preventing free radical to harm the body. This research has a purpose to find out the highest antioxidant activity from three different brands of tea (brand A, B and C) based on SNI (Indonesian National Standard) 01-1902-1995 standard in black tea brewing, using DPPH method. The result showed that brand $\mathrm{C}$ has the highest antioxidant activity among others with $\mathrm{IC}_{50} \mathrm{DPPH}$ value $1800 \mu \mathrm{g} / \mathrm{mL}$, while vitamin C standard had $\mathrm{IC}_{50}$ DPPH value $6,32 \mu \mathrm{g} / \mathrm{mL}$.
\end{abstract}

Keywords: Antioxidant, black tea, three brands, DPPH, vitamin $C$

\section{PENDAHULUAN}

Antioksidan merupakan zat yang dapat menghentikan pembentukan radikal bebas dan reaksi berantai dimana dapat menyebabkan kerusakan sel atau bahkan kematian. Antioksidan dapat berupa senyawa eksogen seperti berasal dari makanan, minuman dan sinar matahari, dan dapat pula berupa senyawa endogen yang berasal dari jalur enzimatik dan non enzimatik (Wahlqvist 2013).

Teh (Camellia sinensis (L.) Kuntze) merupakan tumbuhan yang banyak tumbuh di daerah pengunungan Asia. Awalnya teh banyak ditemukan di sekitar barat daya Cina sampai timur laut India, namun sekarang banyak ditemukan di daerah Asia lain seperti Indonesia. Teh diketahui memiliki manfaat baik untuk 
tubuh. Terdapat banyak kandungan di dalam teh antara lain, polifenol, alkaloid, minyak volatil, polisakarida, asam amino, lemak, vitamin, dan lain-lain. Namun kandungan utama teh adalah antioksidan polifenol yaitu katekin. Antioksidan polifenol memberikan keuntungan bagi kesehatan, yaitu berperan dalam melawan radikal bebas yang berbahaya bagi tubuh, mampu mengurangi resiko penyakit jantung dan dapat menghambat sel kanker kulit. Kandungan polifenol yang terdapat pada teh hitam berkisar antara 3-10\% (Sharangi, 2009).

Secara umum teh diklasifikasikan berdasarkan derajat atau periode dari proses oksidasi atau fermentasi daunnya. Dari perbedaan tersebut dikategorikan ke dalam tiga jenis yaitu, teh hijau, teh hitam dan teh oolong. Teh hijau diproses tanpa fermentasi, teh hitam difermentasi secara penuh sementara teh oolong difermentasi sebagian (Ngure et al., 2008).

Bagian polifenol yang terkandung akan teroksidasi menjadi theaflavins dan thearubigin yang memberikan warna oranye kecoklatan pada teh hitam. Pada saat yang bersamaan juga terbentuk senyawa tidak stabil yang memberi kompleksitas pada aroma teh hitam. Jika dibandingkan dengan teh hijau, teh hitam memiliki 650 senyawa aroma kompleks, sementara teh hijau hanya sebanyak 250 senyawa aroma kompleks (Schoorel and van der Vossen, 2000). Pada penelitian yang dilakukan oleh Bhagwat et al. (2003) ditunjukan bahwa teh hitam memiliki kandungan theaflavins dan thearubigin yang lebih tinggi dari pada teh hijau.

Di Indonesia sendiri terdapat standar baku yang digunakan untuk berbagai macam komoditas, salah satunya teh hitam yang diatur dalam SNI 01-19021995. Di dalam SNI 01-1902-1995 terdapat beberapa hal yang dijelaskan di dalamnya, salah satu yang diatur adalah tata cara penyeduhan teh hitam (Badan Standarisasi Nasional, 1995).

Berdasarkan pemaparan di atas, dapat dirumuskan masalah merek dagang teh manakah yang memiliki kandungan antioksidan paling tinggi dengan penyeduhan teh hitam yang telah diatur oleh SNI.

Tujuan dari penelitian ini adalah untuk mengetahui aktivitas antioksidan tertinggi pada teh hitam dari beberapa merk dagang teh (Merk A, Merk B dan Merk C) menggunakan metode DPPH dengan standar penyeduhan teh sesuai dengan yang diatur dalam SNI 01-19021995 mengenai teh hitam.

\section{METODE PENELITIAN}

\subsection{Alat dan Bahan}

Alat : Timbangan analitik, alat alat gelas, termometer, mikroskop, mikropipet (Eppendorf), spekroskopi UV-Vis 
Perbandingan Aktivitas Antioksidan Dari Seduhan....

(Hewlett Packard 8453), penguap vakum putar (Buchi rotavapor R-215), vortex.

Bahan : Teh hitam Goalpara (A), Teh hitam walini (C) berasal dari PTPN VIII Bandung, Teh hitam Dempo (B) berasal dari PTPN VII Sumatra selatan, DPPH (Sigma-Aldrich).

\subsection{Metode}

\section{1) Pembuatan Seduhan Teh Hitam}

Sampel yang digunakan berupa 3 merk teh hitam berbeda yang diseduh menggunakan pelarut aquadest. Penyeduhan pada teh hitam (10 mg, 20 $\mathrm{mg}, 30 \mathrm{mg}$ ) dilakukan selama enam menit dengan suhu $100^{\circ} \mathrm{C}$. Kemudian filtrat disaring dan diperoleh ekstrak cair.

\section{2) Uji Aktivitas Antioksidan}

Aktivitas radikal bebas DPPH (2,2diphenyl-1-picrylhydrayl) dianalisa berdasarkan persamaan regresi linier dilanjutkan dengan penentuan nilai median Inhibitory Concentration ( $\left.\mathrm{IC}_{50}\right)$. Larutan uji dibuat dengan cara memasukan 0,1 mL ekstrak cair teh hitam yang telah dibuat dengan konsentrasi 1000, 2000 dan $3000 \mu \mathrm{g} / \mathrm{mL}$ ke dalam vial berwarna gelap, kemudian ditambahkan $2 \mathrm{~mL}$ larutan DPPH (60 $\mu \mathrm{g}$ / $\mathrm{mL}$ dalam metanol) dan $2 \mathrm{~mL}$ metanol (Kusumaningrum, 2013). Campuran selanjutnya divortex dan diinkubasi pada suhu kamar selama 30 menit ditempat gelap. Larutan ini selanjutnya diukur absorbansinya pada $\lambda_{\max } 515 \mathrm{~nm}$. Nilai
$\mathrm{IC}_{50}$ kemudian ditentukan. Data hasil pengukuran absorbansi dianalisis persentase aktivitas antioksidannya menggunakan persamaan (Andayani dkk, 2008) berikut :

$\%$ Inhibisi $=\frac{\text { A.kontrol-A.sampel }}{\text { A.kontrol }} \times 100 \%$

Ket: A : Absorbansi

\section{HASIL DAN PEMBAHASAN}

\subsection{Penapisan Fitokimia}

Tabel 1. Hasil Penafisan fitokimia simplisia

\begin{tabular}{|c|c|c|c|}
\hline Golongan Senyawa & Teh A & Teh B & Teh C \\
\hline Alkaloid & - & - & - \\
\hline Flavanoid & $\sqrt{ }$ & $\sqrt{ }$ & $\sqrt{ }$ \\
\hline Tannin & $\sqrt{ }$ & $\sqrt{ }$ & $\sqrt{ }$ \\
\hline Kuinon & - & - & - \\
\hline Fenolat/ Polifenolat & $\sqrt{ }$ & $\sqrt{ }$ & $\sqrt{ }$ \\
\hline Saponin & $\sqrt{7}$ & $\sqrt{ }$ & $\sqrt{7}$ \\
\hline Monoterpen / Sesquiterpen & $\sqrt{ }$ & $\sqrt{ }$ & $\sqrt{ }$ \\
\hline Terpenoid / Steroid & $\sqrt{ }$ & $\sqrt{ }$ & $\sqrt{ }$ \\
\hline
\end{tabular}

\section{Keterangan :}

$(\sqrt{ })=$ terdeteksi

$(-)=$ tidak

terdeteksi

Dari data hasil penafisan fitokimia yang telah dilakukan terhadap simplisia teh hitam A, B dan $\mathrm{C}$ mengandung flavanoid, saponin, fenolat, tanin, monoterpen / sesquiterpen dan triterpenoid / steroid. Alkaloid, kuinon tidak teridentifikasi pada masing-masing teh $\mathrm{A}$, teh $\mathrm{B}$ dan teh $\mathrm{C}$.

\subsection{Uji Aktivitas Antioksidan}

Aktivitas antioksidan yaitu kemampuan suatu bahan yang mengandung antioksidan untuk dapat meredam senyawa radikal bebas yang ada 
disekitarnya. Uji aktivitas antioksidan ini dilakukan secara kuantitatif menggunakan metode DPPH (1,1-diphenyl-2pycrilhydrazil). Pengujian antioksidan dilakukan untuk mengetahui teh hitam mana yang mempunyai aktivitas antioksidan paling tinggi dengan lama penyeduhan dan suhu yang sesuai dengan SNI dari ke tiga merk teh hitam yang berbeda.

Prinsip kerja dari metode DPPH ini adalah proses reduksi senyawa radikal bebas DPPH (1,1-diphenyl-2pycrilhydrazil) oleh antioksidan. Proses reduksi ditandai dengan perubahan warna larutan, yaitu dari warna ungu pekat (senyawa radikal bebas) menjadi warna kuning (senyawa radikal bebas yang tereduksi oleh antioksidan). Pemudaran warna akan mengakibatkan penurunan nilai absorbansi sinar tampak dari spektrofotometer, sehingga semakin rendah nilai absorbansi maka semakin tinggi aktivitas antioksidannya (Ananda, 2009:28).

Metode ini menggunakan $\mathrm{IC}_{50}$ sebagai parameter untuk menentukan konsentrasi senyawa antioksidan yang mampu menghambat $50 \%$ aktivitas radikal bebas DPPH. Semakin kecil nilai $\mathrm{IC}_{50}$, maka semakin tinggi aktivitas antioksidannya. Kemudian untuk menentukan nilai $\mathrm{IC}_{50}$ dibuat kurva hubungan antara konsentrasi ekstrak dan persen inhibisi yang akan menghasilkan persamaan regresi linier (Lung dan Destiani, 2017).

Pada penelitian ini pengujian aktivitas antioksidan dilakukan pada tiga merk teh hitam yang berbeda menggunakan spektrofotometri UV-Vis. Radikal bebas pada penelitian ini digunakan larutan DPPH dengan konsentrasi $60 \mu \mathrm{g} / \mathrm{mL}$. Sebelum dilakukan pengujian aktivitas antioksidan dilakukan pengukuran panjang gelombang maksimum DPPH yang telah dibuat. Hasil dari pengujian ini didapat panjang gelombang maksimum yaitu $515 \mathrm{~nm}$ untuk teh $\mathrm{A}, 515,5 \mathrm{~nm}$ untuk teh $\mathrm{B}$ dan $514,5 \mathrm{~nm}$ untuk teh $\mathrm{C}$.

Senyawa pembanding yang digunakan adalah vitamin C (Asam askorbat), vitamin $\mathrm{C}$ merupakan senyawa antioksidan alami yang sering digunakan sebagai senyawa pembanding dalam pengujian aktivitas antioksidan, karena senyawa antioksidan alami relatif aman dan tidak menimbulkan toksisitas (Lung dan Destiani, 2017).

Berikut hasil absorbansi yang didapat dari hasil pengujian sampel vitamin $\mathrm{C}$ menggunakan spektrofotometer UV-Vis (Tabel 2). 
Perbandingan Aktivitas Antioksidan Dari Seduhan....

Tabel 2. Absorbansi DPPH pada Vitamin C

\begin{tabular}{|c|c|c|c|c|c|c|c|}
\hline \multirow{2}{*}{ Konsentrasi $(\mu \mathrm{g} / \mathrm{mL})$} & \multicolumn{2}{|c|}{ Replikasi 1} & \multicolumn{2}{|c|}{ Replikasi 2} & \multicolumn{2}{|c|}{ Replikasi 3} & \multirow{2}{*}{ Rata-Rata \% inhibisi } \\
\hline & Absorbansi & Inhibisi (\%) & Absorbansi & Inhibisi $(\%)$ & Absorbansi & Inhibisi $(\%)$ & \\
\hline 2 & 0,638 & 0,6695 & 0,627 & 2,3821 & 0,591 & 7,9869 & 3,6795 \\
\hline 4 & 0,562 & 12,5019 & 0,509 & 20,7535 & 0,505 & 21,3763 & 18,2106 \\
\hline 6 & 0,333 & 48,1551 & 0,326 & 49,2449 & 0,308 & 52,0473 & 49,8158 \\
\hline 8 & 0,202 & 68,5505 & 0,199 & 69,0176 & 0,162 & 74,7781 & 70,7821 \\
\hline 10 & 0,091 & 85,8322 & 0,056 & 91,2813 & 0,057 & 91,1256 & 89,413 \\
\hline
\end{tabular}

Untuk melihat hasil peredaman terhadap radikal bebas DPPH pada penelitian ini ekstrak cair teh hitam yang telah dibuat dengan waktu penyeduhan enam menit pada suhu $100^{\circ} \mathrm{C}$ dengan konsentrasi $1000 \mu \mathrm{g} / \mathrm{mL}, 2000 \mu \mathrm{g} / \mathrm{mL}$ dan $3000 \mu \mathrm{g} / \mathrm{mL}$. Setelah diperoleh hasil pengukuran absorbansi menggunakan spektrofotometer UV-Vis dilakukan perhitungan mengunakan rumus \% inhibisi. Hasil pengujian menggunakan spektrofotometer UV-Vis disajikan pada

Tabel 3, 4 dan 5 .

Tabel .3. Absorbansi DPPH pada Teh Hitam A

\begin{tabular}{|c|c|c|c|c|c|c|c|}
\hline \multirow{2}{*}{ Konsentrasi $(\mu \mathrm{g} / \mathrm{mL})$} & \multicolumn{2}{|c|}{ Replikasi 1} & \multicolumn{2}{|c|}{ Replikasi 2} & \multicolumn{2}{|c|}{ Replikasi 3} & \multirow{2}{*}{ Rata-Rata \% inhibis } \\
\hline & Absorbansi & Inhibisi (\%) & Absorbansi & Inhibisi (\%) & Absorbansi & Inhibisi (\%) & \\
\hline kontrol & 0,608 & - & 0,592 & - & 0,588 & - & - \\
\hline 1000 & 0,467 & 21,6443 & 0,447 & 25 & 0,407 & 31,7114 & 26,1186 \\
\hline 2000 & 0,393 & 34,0604 & 0,358 & 39,9329 & 0,338 & 43,2886 & 39,0939 \\
\hline 3000 & 0,319 & 46,4765 & 0,28 & 53,0201 & 0,267 & 55,2013 & 51,5659 \\
\hline
\end{tabular}

Tabel .4. Absorbansi DPPH pada Teh Hitam B

\begin{tabular}{|c|c|c|c|c|c|c|c|}
\hline \multirow{2}{*}{ Konsentrasi $(\mu \mathrm{g} / \mathrm{mL})$} & \multicolumn{2}{|c|}{ Replikasi 1} & \multicolumn{2}{|c|}{ Replikasi2 } & \multicolumn{2}{|c|}{ Replikasi 3} & \multirow{2}{*}{ Rata-Rata \% inhibisi } \\
\hline & Absorbansi & Inhibisi $(\%)$ & Absorbansi & Inhibisi $(\%)$ & Absorbansi & Inhibisi $(\%)$ & \\
\hline Kontrol & 0,646 & - & 0,694 & - & 0,686 & - & - \\
\hline 1000 & 0,445 & 34,1034 & 0,495 & 26,6992 & 0,443 & 34,3995 & 31,734 \\
\hline 2000 & 0,356 & 47,2827 & 0,256 & 62,0909 & 0,226 & 66,5333 & 58,6356 \\
\hline 3000 & 0,23 & 65,9411 & 0,196 & 70,9759 & 0,151 & 77,6396 & 71,5189 \\
\hline
\end{tabular}

Tabel .5. Absorbansi DPPH pada Teh Hitam C

\begin{tabular}{|c|c|c|c|c|c|c|c|}
\hline \multirow{2}{*}{ Konsentrasi $(\mu \mathrm{g} / \mathrm{mL})$} & \multicolumn{2}{|c|}{ Replikasi 1} & \multicolumn{2}{|c|}{ Replikasi 2} & \multicolumn{2}{|c|}{ Replikasi3 } & \multirow{2}{*}{ - Rata-Rata \% inhibisi } \\
\hline & Absorbansi & Inhibisi $(\%)$ & Absorbansi & Inhibisi $(\%)$ & Absorbansi & Inhibisi $(\%)$ & \\
\hline kontrol & 0,7 & - & 0,704 & - & 0,693 & - & - \\
\hline 1000 & 0,594 & 15,0214 & 0,604 & 13,5908 & 0,663 & 5,1502 & 11,2541 \\
\hline 2000 & 0,451 & 35,4792 & 0,498 & 28,7554 & 0,48 & 31,3305 & 31,855 \\
\hline 3000 & 0,361 & 48,3548 & 0,326 & 53,3619 & 0,326 & 53,3619 & 51,6927 \\
\hline
\end{tabular}


Setelah didapat absorbansi untuk melihat tingginya aktivitas antioksidan dari ketiga merk teh hitam dapat dilihat dari nilai $\mathrm{IC}_{50}$ dengan dibuat kurva dengan perbandingan \% inhibisi (y) dan konsentrasi $(\mu \mathrm{g} / \mathrm{mL})$ pada setiap sampel. Sehingga akan diperoleh persamaan regresi linier $\mathrm{y}=\mathrm{bx}+\mathrm{a}$. Kemudian kurva hubungan antara \% inhibisi dan konsentrasi $(\mu \mathrm{g} / \mathrm{mL})$ pada sampel ekstrak cair teh hitam $\mathrm{A}, \mathrm{B}$ dan $\mathrm{C}$ dan vitamin $\mathrm{C}$ disajikan pada Gambar 1, 2, 3 dan 4.

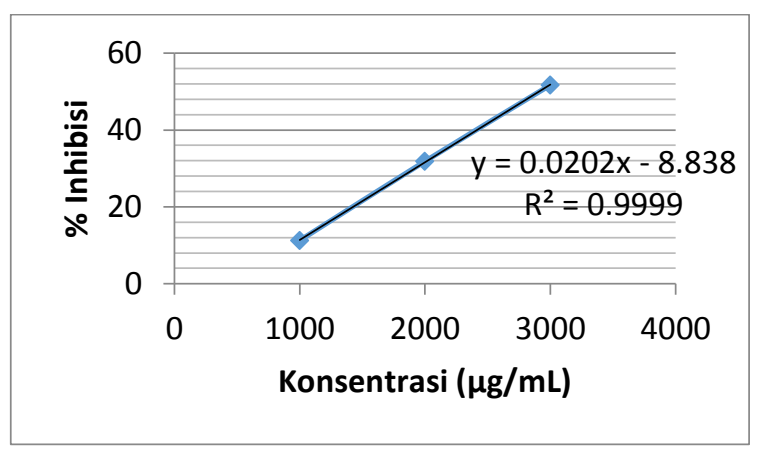

Gambar 1. Kurva hubungan \% inhibisi dengan Konsentrasi pada sampel ekstrak cair teh hitam A

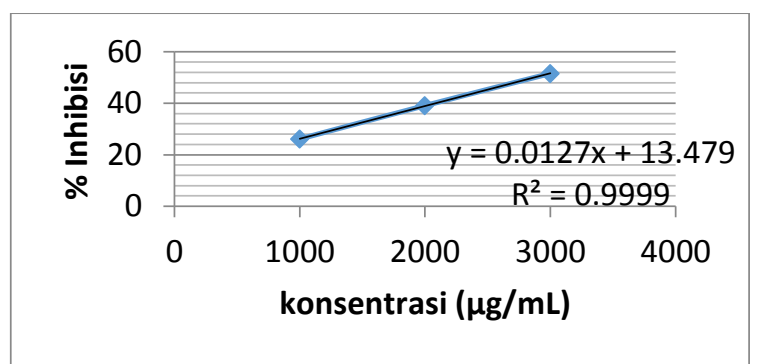

Gambar 2. Kurva hubungan $\%$ inhibisi dengan Konsentrasi pada sampel ekstrak cair teh hitam B

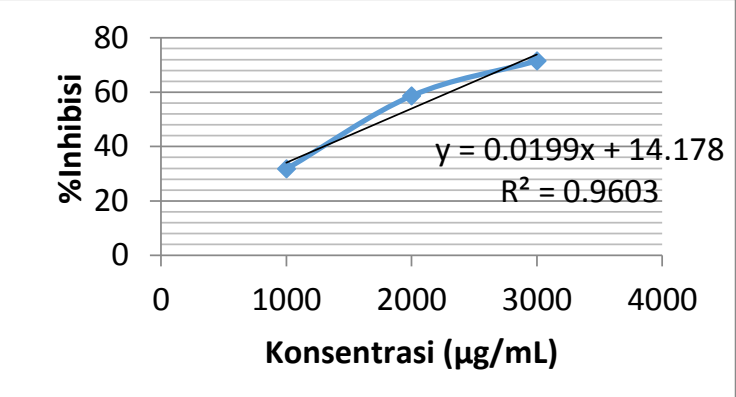

Gambar 3. Kurva hubungan $\%$ inhibisi dengan Konsentrasi pada sampel ekstrak cair teh hitam $\mathrm{C}$

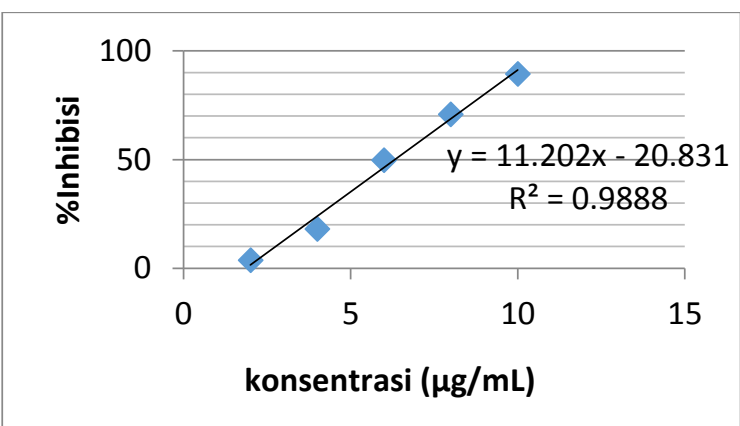

Gambar 4. Kurva hubungan \% inhibisi dengan Konsentrasi pada vitamin C

Dengan diperolehnya persamaan garis linier dari ketiga ekstrak cair teh hitam didapatkan konsentrasi minimum yang dapat meredam radikal bebas $50 \%$ terhadap DPPH sebagai berikut :

Tabel.6 Perbandingan Nilai $\mathrm{IC}_{50}$ seduhan Teh Hitam dan Vitamin C

\begin{tabular}{|l|c|}
\hline \multicolumn{1}{|c|}{ Sample } & IC50 Value $(\boldsymbol{\mu g} / \mathbf{m L} \mathbf{~})$ \\
\hline Teh Hitam (A) & 2875.7 \\
\hline Teh Hitam (B) & 1800.1 \\
\hline Teh Hitam (C) & 2912.7 \\
\hline Vitamin C & 6.32 \\
\hline
\end{tabular}

Dari data yang diperoleh (Tabel 6) dari penelitian ini yang memiliki aktivitas antioksidan yang tinggi dari ketiga merk teh 
hitam adalah teh $\mathrm{B}$, yaitu dengan nilai $\mathrm{IC}_{50}$ $1800,1 \mu \mathrm{g} / \mathrm{mL}$. Namun dari nilai $\mathrm{IC}_{50}$ dapat dilihat bahwa vitamin $\mathrm{C}$ yang digunakan sebagai pembanding aktivitas antioksidan lebih kuat di bandingkan dengan seduhan teh $\mathrm{A}$, teh $\mathrm{B}$ dan teh $\mathrm{C}$ yang memiliki aktivitas lemah. Untuk menghasilkan aktivitas antioksidan yang sama dengan vitamin C perlu peningkatan konsentrasi yang besar pada teh hitam yang dibuat.

\section{KESIMPULAN DAN SARAN}

Hasil penelitian aktivitas antioksidan menggunakan peredaman radikal bebas DPPH dari ketiga merk teh hitam yang berbeda dapat disimpulkan yang memiliki aktivitas antioksidan yang tertinggi adalah teh B yang memiliki nilai $\mathrm{IC}_{50} 1800,1 \mu \mathrm{g} / \mathrm{mL}$. Semakin kecil nilai $\mathrm{IC}_{50}$ maka peredaman radikal bebas akan semakin besar.

\section{UCAPAN TERIMA KASIH}

Terima kasih kepada PT. Pusat Penelitian Teh dan Kina Gambung yang bersedia memberikan saran dan bantuan terkait dengan produk yang digunakan sebagai bahan penelitian.

\section{DAFTAR PUSTAKA}

Ananda, AD., 2009. Aktivitas Antioksidan dan Karakterisasi organoleptik minuman fungsional teh hijau (Camellia sinensis) rempah instant.[Skripsi], Program Studi Gizi Mayarakat dan Sumber Daya
Keluarga,Fakultas Pertanian, Institut Pertanian Bogor, Bogor..

Badan Standarisasi Nasional, 1995. SNI 011902-1995 Teh Hitam. Jakarta: Badan Standarisasi Nasional.

Bhagwat S., Beecher GR., Haytowitz DB., Holden JM., Dwyer J., Peterson J., Gebhardt SE., Eldridge AL., Agarwal S. and Balentine DA., 2003. 'Flavonoid composition of tea: Comparison of black and green teas

Kamus Besar Bahasa Indonesia, 2016. Antioksidan. [Diakses online 26 Desember 2017] https://kbbi.kemdikbud.go.id/entri/anti oksidan

Kumar S., 2014. The Importance of Antioxidant and their role in Pharmaceutical science-A review. Asian journal of Research in Chemistery and Pharmaceutical Science. 1(1): 27-44.

Kusumaningrum R., Supriadi A., Hanggita SJS., 2013. Karakteristik dan Mutu Teh Bunga Lotus (Nelumbo nucifera) Volume II(1)

Lung JKS., dan Destiani DP., 2017. Uji antioksidan vitamin A C E dengan metode DPPH. Suplemen Volume 15(1): 55-62.

Ngure FM., Kanyiri WJ., Mahungu SM., and Shitandi AA., 2009. Catechins depletion patterns in relation to theaflavin and thearubigins formation. Food Chemistry. 115: 8-14.

Sharangi, AB., 2009. Medicinal and therapeutic potentialities of tea (Camellia sinensis L.) - A review, Food Research International. 42(5): 529-530.

Schoorel AF and van der Vossen HAM., 2000. Camellia sinensis (L.) Kuntze. In: van der Vossen, H.A.M. and Wessel, M. (Editors): Plant Resources of SouthEast Asia No 16. Stimulants. Backhuys Publishers, Leiden, the Netherlands. pp.55-6 